\title{
Ontogeny of memory: Examination of a behavioral explanation
}

\author{
JOHN W. KULIG \\ Dartmouth College, Hanover, New Hampshire 03755
}

\begin{abstract}
Three groups of rats were trained in a shock-motivated T-maze position discrimination and then tested for retention with relearning procedures 30 days later. One group trained at 19 days of age retained less than another group trained at $\mathbf{5 0}$ days of age, replicating the ontogeny of memory effect. The third group was trained at 19 days but blinded before training. This group was predicted to show better retention than the normals trained at the same age, according to a behavioral explanation of the ontogeny of memory phenomenon. Contrary to the prediction, the retention of the blind animals was no better than that of their normal counterparts.
\end{abstract}

In a recent review of the animal literature on the ontogeny of memory, Campbell and Coulter (1976) conclude that behaviors acquired by young rats are forgotten more rapidly than the same behaviors learned by adults. Such behaviors include learned fears (Campbell \& Campbell, 1962), discriminated escape (Campbell, Misanin, White, \& Lytle, 1974; Smith, 1968), and avoidance behavior (Feigley \& Spear, 1970; Kirby, 1963). Campbell et al. (1974) outline two explanations, one stressing physiological maturation of the brain, the other, behavioral mechanisms to account for this developmental change in retention. The physiological hypothesis is supported by the fact that guinea pigs, whose central nervous system functioning at birth is mature compared to that of the neonatal rat, do not show such differences in memory for tasks which reveal such differences in rats (Campbell et al., 1974). Retroactive interference has been the most widely cited candidate for a behavioral mechanism. Such an explanation requires either that infant rats are more susceptible to retroactive interference or that they are disposed toward learning more about their environment than are adult rats. Either way, an Interference by Age interaction is predicted, but in a recent test of this hypothesis young rats did not show more forgetting than older rats when amount of intervening experience was manipulated (Parsons \& Spear, 1972).

The possibility that age differences in stimulus coding underlie the observed age differences in memory gave impetus to the present experiment. For example, Tighe (1973), in the study of discrimination learning in children, has provided evidence of a developmental shift

Requests for reprints should be sent to John W. Kulig, Department of Psychology, Dartmouth College, Hanover, New Hampshire 03755. Thanks are due Thomas J. Tighe and Robert N. Leaton, for assistance throughout the course of the research and preparation of the manuscript, and to Lisa Powlison, for critically reading the manuscript. This paper is sponsored by Thomas J. Tighe, who takes full editorial responsibility for its contents. from the learning of stimulus compounds to stimulus components. Similarly, Hebb (1949) has suggested that the stimulus dimensions used by infrahumans for encoding change with age. Such coding shifts occurring during the retention interval would be expected to interfere with retention performance to the degree that the test of retention requires relearning of the appropriate stimulus-response relationships. Thus, an animal that learns a problem in infancy and is tested for relearning as an adult may use different encodings during the learning and relearning sessions, with the consequence that the infant experience cannot aid in construction of an adult solution. On the other hand, an animal that first learns the problem with adult codes will encounter no inconsistency with coding processes used in a later relearning session.

This line of reasoning suggests that procedures which minimize opportunities for coding differences between learning in infancy and retention testing in adulthood would result in better retention performance relative to that normally obtained. One way to reduce such opportunities would be to restrict the range and variety of stimulus dimensions in the initial learning situation. In a typical experiment on ontogeny of memory, a rat learns to choose the nonshocked arm of a $T$ maze. Ordinarily, the task permits solution on the basis of a multiplicity of intra- and extramaze visual cues as well as proprioceptive cues, in compound or as stimulus components. However, if animals were required to solve the problem and take the retention test in the absence of visual stimuli, they would presumably learn the task on the basis of position cues alone, thereby minimizing the possibility of coding shifts between the original and relearning sessions. In the present experiment, visual input was eliminated by blinding rats prior to the learning of a shock-motivated T-maze discrimination. On the basis of the above argument, it was predicted that rats which learned the task as blinded infants would show retention superior to that of sighted peers and retention equivalent to that of adult learners. 
It should be mentioned that the prediction of superior retention for blind rats is not inconsistent with a retroactive interference explanation of the results. That is, if between training and relearning, blind rats learn less than normal rats as a result of their condition, their memory for training would suffer less interference. Given a finding of superior retention by blind rats in this experiment, future research would be necessary to separate interference and coding explanations. However, the possibility that retroactive interference plays a major role in ontogeny of memory in normal rats seems unlikely in light of the results of Parsons and Spear (1972).

\section{METHOD}

\section{Subjects and Apparatus}

Thirty-three male and 30 female albino rats bred and reared in the psychology department vivarium served as subjects. Large litters were culled to eight or nine pups postpartum, and all pups were weaned at 23 days of age.

Two mazes were used for this experiment, a Y maze to measure exploratory behavior and a $\mathrm{T}$ maze for discriminated escape learning and later retention testing. The $Y$ maze was made of wood, with a wire-mesh top, and each arm measured $24 \times 5$ $x 4 \frac{1}{2}$ in. Illumination was provided by either a 7.5 -W red light bulb or normal overhead lighting, depending on the experimental treatment.

The T maze was constructed of Plexiglas, with interchangeable start- and goalboxes. The stem measured $16 \times 4 \frac{1}{2} \times 6$ in. and the arms, $11 \frac{1 / 2}{2} \times 4 \frac{1}{2} \times 6$ in. The start- and goalboxes were $8 \times 4 \frac{1}{2} \times 6$ in. The sides were spray painted gray, and the top was clear Plexiglas. The floors of the maze and endboxes consisted of $1 / 16$-in. brass rods throughout, spaced $1 / 4$ in. apart. The maze was equipped with guillotine doors for each startand goalbox. A .6-mA shock was delivered from a constantcurrent shock source, presented through a grid scrambler and pulsed 7.5 times/sec.

\section{Design and Procedure}

At 16 days of age, one-third of the subjects were anaesthetized and blinded by surgical enucleation of the eyes, while the remaining two-thirds were anaesthetized only. To test for possible surgery-induced depressions in activity levels, all subjects were placed in the $Y$ maze $15 \mathrm{~min} /$ day at 17 and 18 days of age, and the number of arm entries were recorded. Dim red light was in use on the first day, while normal illumination was in effect on the second. ${ }^{1}$

All subjects were trained in a discriminated escape task with apparatus and procedures essentially identical to those used by Campbell et al. (1974). The age groups used here, 19 and 50 days at time of original training, were slightly different than those used by Campbell et al. $(15,17,20,25$, and 35 days at time of original learning). This variation was imposed to maximize age-related differences in retention, and the $T$ maze was scaled in size accordingly.

The blind subjects (Group B-19) and Group N-19, representing one-half of the sighted subjects, received preadaptation to the $T$ maze followed by original learning of the escape response at 19 days of age. The remaining subjects, Group N-50, received identical treatment at 50 days of age. Preadaptation consisted of allowing each subject to explore the interior of the $T$ maze for $5 \mathrm{~min}$. The main task was a shock-motivated position discrimination, consisting of 40 trials in two 20 -trial sessions separated by $6 \mathrm{~h}$. Each trial began by opening the guillotine door of the startbox concurrently with shock onset. The floor of the entire maze except the floor area inside the correct goalbox (left or right) was electrified. Shock remained on until the subject entered the correct goalbox, at which time shock was removed from the entire maze and the guillotine door closed behind the subject. During the 45 -sec intertrial interval, the correct goalbox was interchanged with the startbox. Shock was unavoidable and remained on until the correct goalbox had been entered.

All subjects were trained to escape to the goalbox opposite the position (left or right) of their initial preference, which was determined by a preliminary trial. This trial preceded and was continuous with the first block of 20 training trials, and was identical to the training trials except that shock was initially present in both goalboxes until the subject entered one of them. At that time, shock was removed from the opposite goalbox for the remainder of the preliminary trial and for the remaining training and test trials of that subject. The preliminary trial was excluded from any graphic and statistical analyses. A correct trial was scored only if an animal entered the correct goalbox without entering the incorrect arm (excluding the tail) on that trial. An error trial was scored if the subject made one or more entries into the incorrect arm on a trial.

Retention tests were administered to all subjects 30 days after original learning and consisted of five relearning trials identical in procedure to original learning trials. No preadaptation to the maze was given prior to relearning.

There were 21 subjects per group, approximately half of whom were male and half female within each group. When not being trained or tested, all subjects remained with their respective litters until 23 days of age and thereafter resided in individual cages.

\section{RESULTS}

Figure 1 shows amount of exploratory behavior expressed as number of arm entrances per 5-min time block for the three groups on both days of exploratory testing. Analysis of variance was performed with the factors of time blocks, days, and experimental condition (B-19, N-19, and N-50). There was a significant timeblock effect $(F=148.7, \mathrm{df}=2 / 120, \mathrm{p}<.0001)$, substantiating the decline seen graphically within the 15 -min session. Differences between the 2 days were significant $(\mathrm{F}=68.39, \mathrm{df}=1 / 60, \mathrm{p}<.0001)$, as was the Days by Condition interaction $(\mathrm{F}=3.92, \mathrm{df}=1 / 60$, $\mathrm{p}<.05$ ). This interaction is explainable by the fact that $\mathrm{N}-19$ and $\mathrm{N}-50$ subjects showed more of a decline between Day 1 and Day 2 than did B-19 subjects. The main effect of conditions failed to reach significance $(\mathrm{F}=2.66, \mathrm{df}=2 / 60, \mathrm{p}<.10)$, and the remaining interactions were not significant.

Figure 2 shows the original learning and retention data of the escape response for the three experimental conditions, expressed as percent correct per block of five trials. Looking first at original learning performance, an analysis of variance of the number of correct responses per block of five trials revealed a significant effect of trials $(F=9.0139$, df $=7 / 420, p<.0001)$, demonstrating acquisition of the response across trials, and an experimental condition effect $(F=8.68$, $\mathrm{df}=2 / 60, \mathrm{p}<.001)$. Newman-Keuls comparisons of group differences revealed that Group N-19 did not differ from Group N-50, but that both sighted groups differed from B-19 subjects ( $p<.05$ for both). To determine whether the groups differed at the end of acqui- 


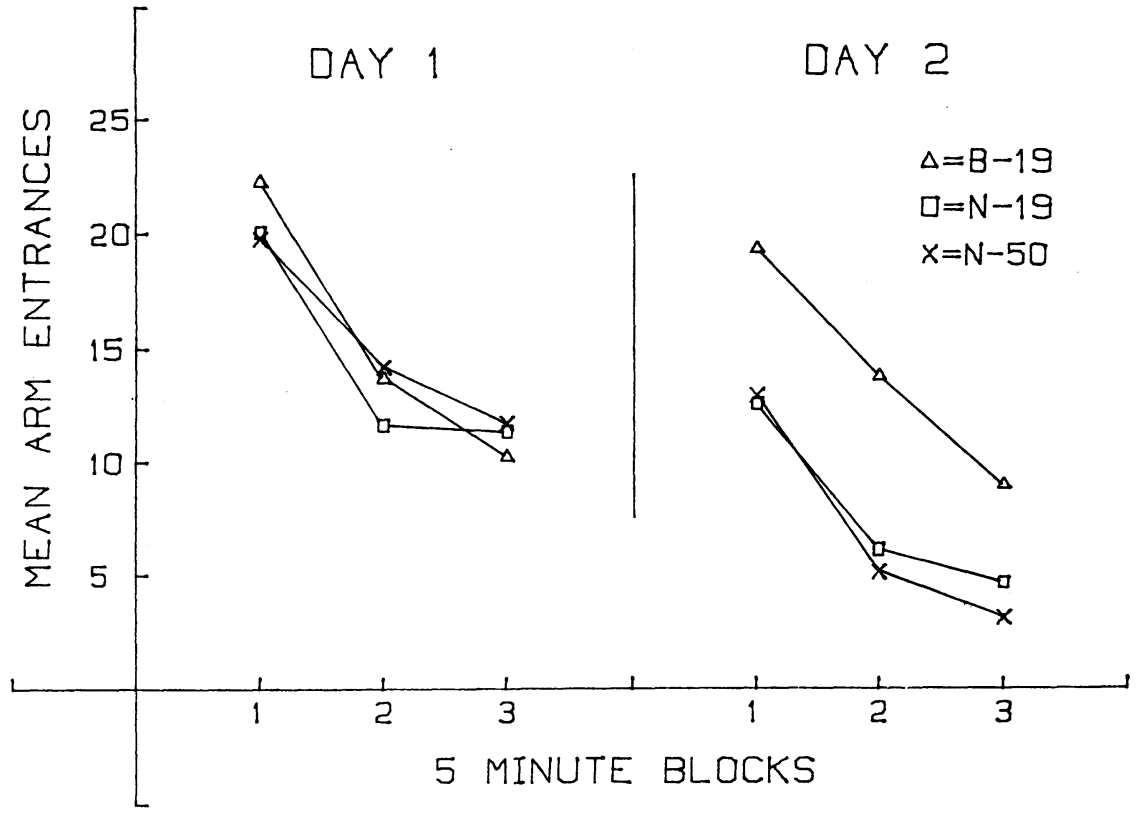

Figure 1. Number of arm entrances for the three experimental groups under conditions of dim red illumination (Day 1) and normal illumination (Day 2).

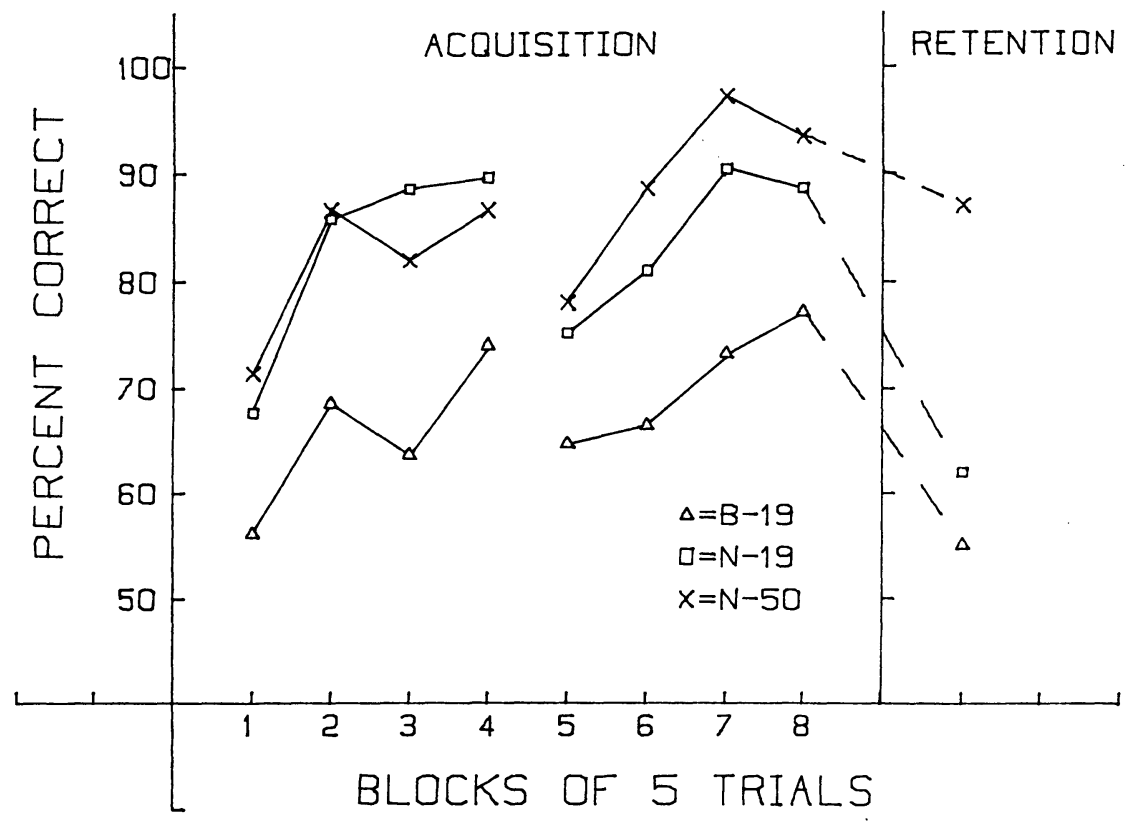

Figure 2. Group learning and retention performance of a shock-motivated $T$-maze escape response.

sition, Scheffé tests were performed on only the last five trials. Group N-19 did not differ from Group N-50, but B-19 differed from both $\mathrm{N}-19(\mathrm{p}=.053)$ and $\mathrm{N}-50$ $(p<.01)$. The Trial Block by Condition interaction was not significant $(F<1)$.

Looking next at retention results, number correct out of five relearning trials was analyzed, using the Scheffé test on group means. B-19 and N-19 subjects did not differ on the retention measure, but $\mathrm{N}-50$ subjects were better than $\mathrm{N}-19(\mathrm{p}<.01)$ and B-19 $(p<.001)$. Because the analyses of original learning found differences in the degree of learning among groups, additional analyses of relearning were performed using only those subjects within each condition that scored $80 \%$ correct or better on their last five acquisition trials. There were 14,18 , and 20 such subjects in 
Groups B-19, N-19, and N-50, respectively. Again, Groups B-19, and N-19 did not differ in retention performance, and N-50 subjects performed better than both N-19 and B-19 subjects $(p<.001$ for both).

\section{DISCUSSION}

This study replicates the ontogeny of memory phenomenon in a shock-motivated, discriminated escape task, as evidenced by retention differences between normal rats trained at 19 and at 50 days of age, and tested after a 30-day retention interval. In Campbell et al. (1974), rats trained at 15, 17, and 20 days of age retained less than rats trained at 25 and 35 days, following 7- and 14-day retention intervals.

The preexperimental hypothesis was that the poorer retention of rats trained at younger ages is due to a developmental shift in the nature of stimulus coding occurring between original training and relearning sessions. The prediction from this hypothesis, that blind rats trained at 19 days of age would show better retention than normals trained at the same age, was not confirmed. Both younger groups retained the task equally poorly compared to the adult rats.

The poor performance of the blind rats on both the learning and relearning measures cannot be attributed to a suppression of activity levels produced by the surgical operation, since the Y-maze exploratory test showed these animals to be even more active than sighted peers under normal illumination, the lighting condition used in training and relearning. Further, the poorer original learning of the blind rats cannot account for their poor retention, as the comparison of the three groups involving only those animals that scored $80 \%$ or better at the end of original learning did not alter the outcome pattern.

The results, then, weigh against the hypothesis that the poorer retention of young rats in ontogeny of memory experiments is due to a shift in the type of stimulus coding occurring between original learning and later retention testing. The demonstration of retention losses for blind as well as normal rats extends the range of conditions in which the ontogeny of memory phenomenon has been seen and strengthens the case for the robustness of the effect. Further, these results add indirect support for the contention (Campbell et al., 1974) that the locus of the ontogeny of memory effect lies in the physiological maturation of the central nervous system, rather than in behavioral mechanisms.

\section{REFERENCES}

Campbell, B. A., \& Campbell, E. H. Retention and extinction of learned fear in infant and adult rats. Journal of Comparative Physiological Psychology, 1962, 55, 1-8.

Campbell, B. A., \& Coulter, X. Ontogeny of learning and memory. In M. Rosenzweig \& E. Bennet (Eds.), Neural mechanisms of learning and memory. Cambridge: M.I.T. Press, 1976.

Campbell, B. A., Misanin, J. R., White, B. C., \& Lytle, L. D. Species differences in ontogeny of memory: Indirect support for neural maturation as a determinant of forgetting. Journal of Comparative Physiological Psychology, 1974, 87, 193-202.

Feigley, D. A., \& Spear, N. E. Effect of age and punishment condition on long-term retention by the rat of active- and passive-avoidance learning. Journal of Comparative Physiological Psychology, 1970, 73, 515-526.

HeBв, D. O. The organization of behavior. New York: Wiley, 1949.

KIRBY, R. H. Acquisition, extinction, and retention of an avoidance response in rats as a function of age. Journal of Comparative Physiological Psychology, 1963, 56, 158-162.

Parsons, P. J., \& Spear, N. E. Long term retention of avoidance learning by immature and adult rats as a function of environmental enrichment. Journal of Comparative Physiological Psychology, 1972, 80, 297-303.

SMITH, N. Effects of interpolated learning on retention of an escape response in rats as a function of age. Journal of Comparative Physiological Psychology, 1968, 65, 422-426.

Tighe, T. J. Subproblem analysis of discrimination learning. In G. H. Bower (Ed.), The psychology of learning and motivation (Vol. 7). New York: Academic Press, 1973.

\section{NOTE}

1. Pilot work indicated that blind subjects are more active than sighted subjects when allowed to explore the $\mathrm{Y}$ maze under conditions of normal illumination $24 \mathrm{~h}$ after the surgical and anaesthetization procedures. Accordingly, it was deemed advisable to compare the activity of blind and normal subjects, both with very low illumination (i.e., the dim red light) and with normal illumination.

(Received for publication November 22, 1976.) 